\title{
Combination Nucleos(t)ide Analogue as Initial Treatment for Chronic Hepatitis B: Have We Put This to Rest?
}

See Article on Page 505

$\longrightarrow$ ombination nucleos(t)ide analogs (NUCs) had been advocated as the initial treatment of chronic hepatitis $B$ when lamivudine and adefovir dipivoxil (ADV) were the only approved NUCs for hepatitis B. These drugs had weak antiviral activity and/or low barrier to resistance with rates of genotypic resistance of $70 \%$ and $29 \%$, respectively, after 5 years of continuous treatment. ${ }^{1,2}$ Borrowing from lessons learned in development of treatment for human immunodeficiency virus infection, virologists warned that a combination of NUCs with no cross-resistance would be necessary to maintain long-term suppression of hepatitis B virus (HBV) replication.

In the past 7 years, three additional NUCs have been approved for hepatitis B. Of these, entecavir (ETV) and tenofovir disoproxil fumarate (TDF) have been shown to have a very high barrier to resistance. Phase III clinical trials found that the incidence of genotypic resistance was $1.2 \%$ and $0 \%$ after 5 years of ETV and TDF monotherapy in NUC-naïve patients, respectively. ${ }^{3,4}$ Among hepatitis $\mathrm{B}$ e antigen ( $\mathrm{HBeAg}$ )positive patients, $94 \%$ of ETV-treated patients had HBV DNA $<300$ copies $/ \mathrm{mL}$ and $97 \%$ of TDFtreated patients had HBV DNA $<400$ copies $/ \mathrm{mL}$ at Year $5.4,5$ Although the design of both trials left room for doubt, these data showed that monotherapy with ETV or TDF can maintain viral suppression in the vast majority of patients with chronic hepatitis B for at least 5 years.

Abbreviations: $A D V$, adefovir dipivoxil; ETV, entecavir; FTC, emtricitabine; $H B e A g$, hepatitis $B$ e antigen; $H B V$, hepatitis $B$ virus; $H V L$, high baseline viral load; $N U C s$, nucleos $(t)$ ide analogs; TDF, tenofovir disoproxil fumarate.

Address reprint requests to: Anna S.F. Lok, M.D., Division of Gastroenterology and Hepatology, University of Michigan Health System, 1500 East Medical Center Dr., 3912 Taubman Center, SPC 5362, Ann Arbor, MI 48109. E-mail: aslok@umich.edu; fax: 734-936-7392.

Copyright $\odot 2013$ by the American Association for the Study of Liver Diseases. View this article online at wileyonlinelibrary.com.

DOI 10.1002/hep.26337

Potential conflict of interest: Research grants: Bristol-Myers Squibb, Gilead, Merck. Advisory panel: Gilead, GlaxoSmithKline, Novartis, Merck, Roche.
In the phase III ETV trial, only 183 of 354 patients were enrolled in the roll-over study, some patients had a short gap in treatment between Years 2 and 3, a small number of patients received a combination of lamivudine and ETV for a short duration, and all patients received a higher dose of ETV $(1.0 \mathrm{mg})$ from Year 3 onward. ${ }^{5}$ Nevertheless, other studies in which ETV $0.5 \mathrm{mg}$ was administered continuously confirmed that $>90 \%$ of patients had undetectable HBV DNA and $0 \%-1 \%$ had genotypic resistance after 3-4 years of treatment (Fig. 1). ${ }^{6-10}$ In the phase III TDF trial, patients with confirmed HBV DNA $\geq 400$ copies $/ \mathrm{mL}$ on or after Week 72 were eligible to add emtricitabine (FTC) to TDF and 34 of 51 eligible patients did so. ${ }^{4,11}$ A multicenter field study of TDF monotherapy in Italy confirmed that HBV DNA was undetectable in $95 \% \mathrm{HBeAg}$-positive and in $98 \% \mathrm{HBeAg}$-negative patients at Year 3 in the absence of FTC rescue. ${ }^{12}$

These additional studies support the optimism that monotherapy with ETV or TDF would be sufficient for the vast majority of NUC-naïve patients with chronic hepatitis B. A lingering question is whether this optimism can be applied to patients with high baseline viral load.

In this issue of Hepatology, Gordon et al. ${ }^{13}$ reported the results of a subgroup analysis of the phase III TDF trial. Eligible patients (HBeAg-positive and $\mathrm{HBeAg}$-negative) were randomized to receive TDF $300 \mathrm{mg}$ daily or ADV $10 \mathrm{mg}$ daily for 48 weeks and then open-label TDF for an additional 192 weeks. Of 641 patients enrolled in the trial, 129 (118 HBeAg-positive) had high baseline viral load (HVL) defined as HBV DNA $\geq 9$ $\log _{10}$ copies $/ \mathrm{mL}\left(8.24 \log _{10} \mathrm{IU} / \mathrm{mL}\right)$. At Week 240 ( Year 5 ), $96.1 \%$ of HVL and $98.7 \%$ of non-HVL patients on treatment achieved HBV DNA $<400$ copies/ $\mathrm{mL}$. Both groups had similar rates of histologic regression between baseline and Week 240. Patients with HVL generally took longer to achieve HBV DNA $<400$ copies/ $\mathrm{mL}$ but had caught up with the non-HVL patients by Week 96. The authors stated that no patient with baseline HVL had persistent viremia at Week 240 or amino acid substitutions associated with TDF resistance.

These results are remarkable and suggest that monotherapy with a potent NUC that has a high barrier to 


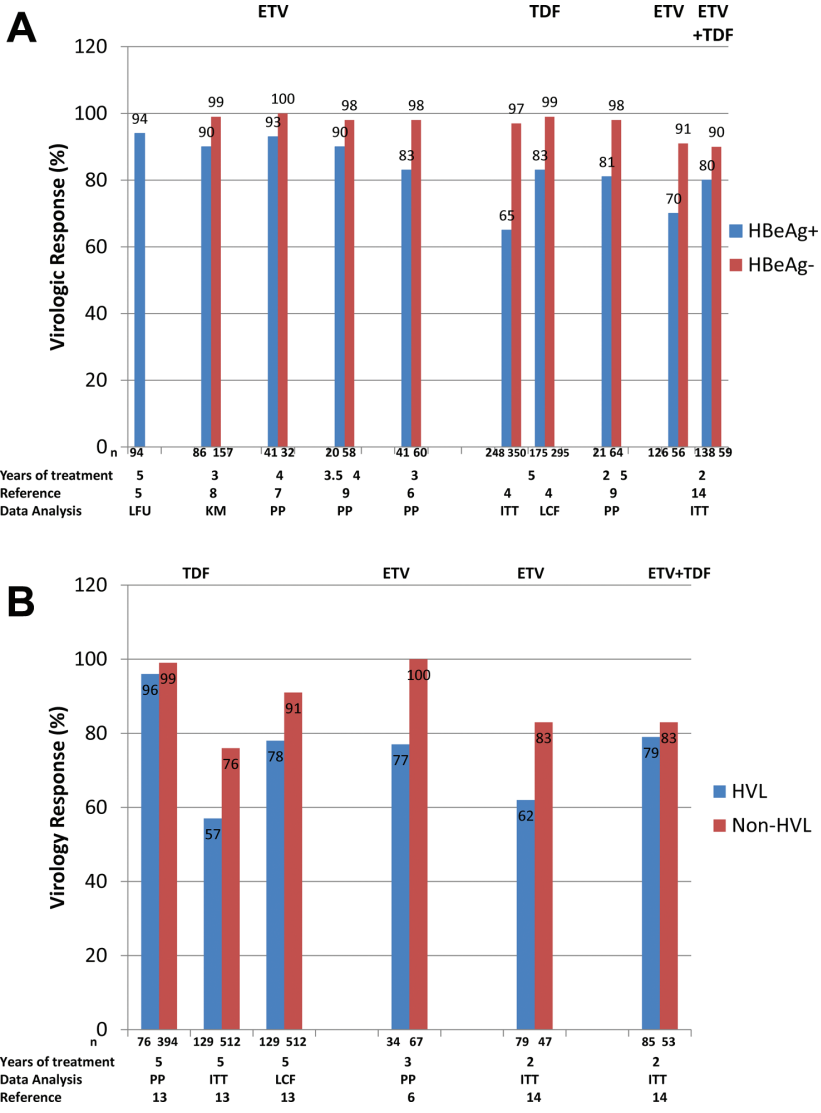

Fig. 1. Virologic response after 2-5 years of treatment with entecavir (ETV) or tenofovir disoproxil fumarate (TDF) monotherapy or combination of ETV plus TDF in nucleos(t)ide-naïve patients with chronic hepatitis $\mathrm{B},(\mathrm{A}) \mathrm{HBeAg}+$ and $\mathrm{HBeAg}-$ patients, and (B) patients with high versus not high viral load (HVL). Different definitions were used for virologic response and high viral load in different studies. LFU $=$ subset of patients with long-term follow-up; KM = Kaplan-Meier probability of response; PP $=$ per protocol analysis of patients with data at that timepoint; ITT = intention to treat analysis with missing data counted as failure; LCF $=$ last result carried forward.

resistance such as TDF is sufficient in maintaining viral suppression during long-term treatment even in patients with HVL. However, the results should be interpreted with caution. Persistent viremia in this study was defined as never having HBV DNA $<400$ copies $/ \mathrm{mL}$ and this endpoint was only reported on patients who remained on treatment at Week 240. Thus, patients with HBV DNA $<400$ copies $/ \mathrm{mL}$ at a single timepoint and higher levels of HBV DNA subsequently would not be considered to have persistent viremia and those who were no longer on treatment at Week 240 were not counted. Of the 129 patients with baseline HVL, 46 discontinued the study before Week 240 of whom 28 had HBV DNA $<400$ copies/mL at the last visit. In the remaining 83 patients, 73 had HBV DNA $<400$ copies/mL, three had HBV DNA $\geq 400$ copies $/ \mathrm{mL}$, and HBV DNA of the other seven were unknown at Week 240. Thus, based on intention to treat analysis, only $56.6 \%(73 / 129)$ patients had HBV DNA $<400$ copies $/ \mathrm{mL}$ at Week 240 . If the last result was carried forward, $78.3 \%(101 / 129)$ patients had HBV DNA < 400 copies/mL. By contrast, HBV DNA $<400$ copies $/ \mathrm{mL}$ at Week 240 was achieved in $76.0 \%$ (389/512) non-HVL patients by intention to treat analysis and in $91.0 \%(466 / 512)$ if the last result was carried forward. Furthermore, 35 HVL patients were eligible to add FTC between Week 72 and 240 and 28 eligible plus one noneligible patient had FTC added. Adding FTC did not appear to affect HBV DNA outcomes, with $66 \%(19 / 29)$ on FTC/TDF and $86 \%(6 / 7)$ on TDF having HBV DNA $<400$ copies/ $\mathrm{mL}$ at Week 240 or last visit. The difference was not statistically significant but this may be related to the small number of patients. HBV DNA levels of the 11 patients with $\mathrm{HBV}$ DNA $\geq 400$ copies $/ \mathrm{mL}$ were not provided.

That patients with HVL take longer to achieve virologic response had also been observed by other investigators. Yuen et al. ${ }^{6}$ studied 222 NUC-naïve patients and found that $100 \%$ and $76.5 \%$ of patients with baseline $\mathrm{HBV}$ DNA $<$ and $\geq 8 \log _{10}$ copies $/ \mathrm{mL}$, respectively, had undetectable HBV DNA at Year 3 of ETV therapy. The only patient in whom ETV resistance was detected had baseline HBV DNA $8.1 \log _{10}$ copies/mL. In a randomized trial comparing ETV monotherapy versus combination of ETV plus TDF in NUC naïve patients, Lok et al. ${ }^{14}$ showed that $76.4 \%$ and $83.2 \%$ patients, respectively, achieved the primary endpoint of HBV DNA $<50 \mathrm{IU} / \mathrm{mL}(\sim 300$ copies $/ \mathrm{mL})$ at Week $96(P=0.088)$. However, a significant difference was observed at Week 96 in HBeAg-positive patients with HVL (defined as HBV DNA $8 \log _{10} \mathrm{IU} / \mathrm{mL}$ ), $62.0 \%$ versus $78.8 \%(P=0.018)$ and in the entire cohort at Week $48,70.3 \%$ versus $80.2 \%(P=0.026)$.

A key question is whether more rapid suppression of HBV replication is clinically relevant. Rapid viral suppression is important in preventing antiviral drug resistance when NUCs with a low barrier to resistance such as lamivudine or telbivudine are used. ${ }^{15,16}$ The impact seems to be small with ETV or TDF. Rapid viral suppression may be important in patients with acute liver failure, severe exacerbation of chronic hepatitis B, or decompensated cirrhosis but there is no evidence to support this notion. Rapid viral suppression may also be important in patients with high levels of HBV DNA who are about to start immunosuppressive therapy; however, data to substantiate this are not available.

In summary, existing data support that initial treatment with combination NUCs is not necessary for the 
vast majority of patients with chronic hepatitis $\mathrm{B}$ when ETV or TDF is used, and while combination therapy may accelerate viral suppression in patients with high baseline viral load, in most instances the marginal clinical benefit does not justify the added cost.

AnNa Suk-Fong LoK, M.D. University of Michigan Ann Arbor, MI

\section{References}

1. Lok AS, Lai CL, Leung N, Yao GB, Cui ZY, Schiff ER, et al. Longterm safety of lamivudine treatment in patients with chronic hepatitis B. Gastroenterology 2003;125:1714-1722.

2. Hadziyannis SJ, Tassopoulos NC, Heathoote EJ, Chang TT, Kitis G, Rizzetto $M$, et al. Long-term therapy with adefovir dipivoxil for HBeAg-negative chronic hepatitis B for up to 5 years. Gastroenterology 2006;131:1743-1751.

3. Tenney DJ, Rose RE, Baldick CJ, Pokornowski KA, Eggers BJ, Fang J, et al. Long-term monitoring shows hepatitis B virus resistance to entecavir in nucleoside-naive patients is rare through 5 years of therapy. Hepatology 2009; 49:1503-1514.

4. Marcellin P, Gane E, Buti M, Afdhal N, Sievert W, Jacobson IM, et al. Regression of cirrhosis during treatment with tenofovir disoproxil fumarate for chronic hepatitis B: a 5-year open-label follow-up study. Lancet 2013;381:468-475.

5. Chang TT, Lai CL, Kew Yoon S, Lee SS, Coelho HS, Carrilho FJ, et al. Entecavir treatment for up to 5 years in patients with hepatitis B e antigen-positive chronic hepatitis B. Hepatology 2010;51:422-430.

6. Yuen MF, Seto WK, Fung J, Wong DK, Yuen JC, Lai CL. Three years of continuous entecavir therapy in treatment-naive chronic hepatitis B patients: viral suppression, viral resistance, and clinical safety. Am J Gastroenterol 2011;106:1264-1271.

7. Ono A, Suzuki F, Kawamura Y, Sezaki H, Hosaka T, Akuta N, et al. Long-term continuous entecavir therapy in nucleos(t)ide-naive chronic hepatitis B patients. J Hepatol 2012;57:508-514.
8. Zoutendijk R, Reijnders JG, Brown A, Zoulim F, Mutimer D, Deterding $\mathrm{K}$, et al. Entecavir treatment for chronic hepatitis $\mathrm{B}$ : adaptation is not needed for the majority of naive patients with a partial virological response. Hepatology 2011;54:443-451.

9. Lampertico P, Vigano M, Soffredini R, Facchetti F, Minola E, Fracassetti $\mathrm{O}$, et al. Entecavir monotherapy in 418 NUC-naive patients with chronic hepatitis B from field practice: high efficacy and favorable safety profile over 3 years of treatment. Hepatology 2011;54(suppl 1): 1043A.

10. Yokosuka O, Takaguchi K, Fujioka S, Shindo M, Chayama K, Kobashi $\mathrm{H}$, et al. Long-term use of entecavir in nucleoside-naive Japanese patients with chronic hepatitis B infection. J Hepatol 2010;52: 791-799.

11. Snow-Lampart A, Chappell B, Curtis M, Zhu Y, Myrick F, Schawalder $\mathrm{J}$, et al. No resistance to tenofovir disoproxil fumarate detected after up to 144 weeks of therapy in patients monoinfected with chronic hepatitis B virus. Hepatology 2011;53:763-773.

12. Lampertico P, Soffredini R, Vigano M, Yurdaaydin C, Idilman R, Papatheodoridis GV, et al. Tenofovir monotherapy suppressed viral suppression in most field practice, treatment-naive patients with chronic hepatitis B followed for 3 years in a multicenter European study. Hepatology 2012;56(suppl):389A.

13. Gordon SC, Krastev Z, Horban A, Petersen J, Sperl J, Dinh P, et al. Efficacy of tenofavir disoproxil fumarate at 240 weeks in patients with chronic hepatitis B with high baseline viral $\operatorname{load}(\geq 9 \log 10$ copies $/ \mathrm{mL}$ ). Hepatology 2013;58:505-513.

14. Lok AS, Trinh H, Carosi G, Akarca US, Gadano A, Habersetzer F, et al. Efficacy of entecavir with or without tenofovir disoproxil fumarate for nucleos $(\mathrm{t})$ ide-naive patients with chronic hepatitis $\mathrm{B}$. Gastroenterology 2012;143:619-628 e1.

15. Yuen MF, Sablon E, Hui CK, Yuan HJ, Decraemer H, Lai CL. Factors associated with hepatitis B virus DNA breakthrough in patients receiving prolonged lamivudine therapy. Hepatology 2001;34:785-791.

16. Zeuzem S, Gane E, Liaw YF, Lim SG, DiBisceglie A, Buti M, et al. Baseline characteristics and early on-treatment response predict the outcomes of 2 years of telbivudine treatment of chronic hepatitis B. J Hepatol 2009;51:11-20. 